Е. И. Грушова, М. В. Станько, И. Н. Хатько

Белорусский государственный технологический университет

\title{
ВЛИЯНИЕ ТЯЖЕЛОЙ СМОЛЫ ПИРОЛИЗА НА ПРОЦЕСС ОКИСЛЕНИЯ НЕФТЯНОГО ГУДРОНА
}

\begin{abstract}
Приводятся результаты исследования процесса окисления нефтяного гудрона в присутствии добавки модификатора. В качестве последней использовали побочный продукт пиролиза легких углеводородов - тяжелую смолу пиролиза в количестве 10 мас. \% от окисляемого гудрона. Битум получали окислением гудрона кислорода воздуха при $200^{\circ} \mathrm{C}$ в течение 6 ч. Анализ продуктов окисления позволил установить, что на их качество (температуру размягчения, пенетрацию), структурно-групповой состав, исследованный методом ИК-спектрометрии, воздействует добавка тяжелой смолы пиролиза. Наличие в смоле соединений с ненасыщенными связями даже при отсутствии инициаторов (или катализаторов) и относительно мягких условиях окисления способствует структурированию окисляемого гудрона.

Обработка исходной сырьевой смеси СВЧ-излучением несколько усиливает этот эффект, повидимому, за счет изменения дисперсионного состояния исходного сырья.
\end{abstract}

Ключевые слова: гудрон, модификатор, тяжелая смола пиролиза, окисление, СВЧ-излучение, битум.

Для цитирования: Грушова Е. И., Станько М. В., Хатько И. Н. Влияние тяжелой смолы пиролиза на процесс окисления нефтяного гудрона // Труды БГТУ. Сер. 2, Химические технологии, биотехнологии, геоэкология. 2021. № 1 (241). С. 57-62.

\section{E. I. Grushova, M. V. Stan'ko, I. N. Khat'ko \\ Belarusian State Technological University}

\section{INFLUENCE OF HEAVY PYROLYSIS RESIN ON THE PROCESS OF OIL TAR OXIDATION}

The results of the study of the process of oil tar oxidation in the presence of a modifier additive are presented. The latter was used as a by - product of pyrolysis of light hydrocarbons-heavy pyrolysis resin in the amount of $10 \mathrm{wt}$. $\%$ of the oxidized tar. Bitumen was obtained by oxidation of tar with air oxygen at $200^{\circ} \mathrm{C}$ for 6 hours. Analysis of the oxidation products allowed us to establish that their quality (softening temperature, penetration), structural and group composition, studied by IR spectrometry, is affected by the addition of heavy pyrolysis resin. The presence of compounds with unsaturated bonds in the resin, even in the absence of initiators (or catalysts) and relatively soft oxidation conditions, contributes to the structuring of the oxidized tar.

Treatment of the initial raw material mixture with microwave radiation somewhat enhances this effect, apparently due to changes in the dispersion state of the raw material.

Key words: tar, modifier, heavy pyrolysis resin, oxidation, microwave radiation, bitumen.

For citation: Grushova E. I., Stan'ko M. V., Khat'ko I. N. Influence of heavy pyrolysis resin on the process of oil tar oxidation. Proceedings of BSTU, issue 2, Chemical Engineering, Biotechnologies, Geoecology, 2021, no. 1 (241), pp. 57-62 (In Russian).

Введение. Повышение эффективности переработки нефти и качества выпускаемых нефтепродуктов, к которым относятся и нефтяные битумы, это основные задачи, которые стоят перед современной нефтепереработкой. В связи с этим важное значение имеют исследования, направленные на разработку рациональных методов совершенствования технологии производства нефтяного битума как одного из наиболее распространенных инженерно-строительных материалов.

В настоящее время для регулирования качества битума используют различные технологические приемы, среди которых можно выделить следующие [1-17]:
- применение в качестве компонентов сырья или добавок к сырью продуктов, содержащих в большом количестве смолисто-асфальтеновые вещества, полициклические ароматические углеводороды (асфальты деасфальтизации, экстракты селективной очистки масел, гудроны, тяжелые остатки каталитического крекинга, остатки висбрекинга);

- использование веществ, катализирующих или инициирующих процесс окисления гудрона и, соответственно, не только ускоряющих процесс, но и влияющих на свойства получаемого продукта (хлорид железа, катализаторный шлам производства капролактама, циклогексанон); 
- введение добавок функционализированных соединений, обеспечивающих структурирование нефтяной дисперсной системы за счет образования новых химических связей (многоатомные спирты, диизоцианаты);

- активация исходного нефтехимического сырья воздействием энергетических, электромагнитных, акустических полей;

- модификация битумов полимерами, адгезионными добавками для коррекции физикохимических свойств и эксплуатационных характеристик товарной продукции;

- совершенствование аппаратурного оформления технологического процесса получения битума.

Для улучшения качества окисленного битума чаще всего используются методы компаундирования товарного битума с полимерами [3-5]. Оценка этого направления с технической и экономической точек зрения приводит к выводу, что полимерные добавки (компоненты) должны быть доступны и рентабельны в применении, не разрушаться и хорошо совмещаться с битумом при смешении на обычном оборудовании при температурах, традиционных для приготовления асфальтобетонных смесей, а также в реальных условиях эксплуатации дорожных покрытий.

Кроме того, использование в составе битумных вяжущих полимеров существенно повышает их себестоимость как за счет высокой стоимости вводимого в битум компонента, так и за счет более энергоемкой технологии совмещения битума с полимером $[1,2]$. Однако полимерные компоненты вяжущего в преобладающем большинстве случаев не взаимодействуют химически с молекулами битума и, соответственно, не оказывают влияние на процесс окисления, а только модифицируют свойства конечного продукта. Чтобы обеспечить совместимость тех или иных составляющих битума с полимером, требуется специальная научная проработка, оптимизация условий и т. п.

В связи с вышеизложенным интерес, по-видимому, представляет направление технологии получения окисленного битума, основанное на окислении сырья совместно с модифицирующими добавками, которые влияют на дисперсное состояние и реакционную способность сырья $[6,7,12,13]$.

Основная часть. В данной работе стояла задача исследовать в роли аддитива-модификатора окисляемого гудрона тяжелую смолу пиролиза (ТСП). Для совместного окисления с гудроном использовали образец ТСП, полученной на заводе «Полимир» ОАО «Нафтан» (Новополоцк), основные показатели которой представлены в табл. 1.

ТСП легких углеводородов составляет около $20 \%$ жидких продуктов пиролиза. Относительно высокое содержание в ТСП ароматических углеводородов, особенно полициклических, и достаточно высокое значение йодного числа, указывающее на значительное содержание непредельных углеводородов, свидетельствует о склонности ТСП к реакциям конденсации, полимеризации с образованием продуктов, обладающих высокими связующими свойствами [7].

Таблица 1

Основные показатели тяжелой смолы пиролиза

\begin{tabular}{|l|c|}
\hline \multicolumn{1}{|c|}{ Показатель } & $\begin{array}{c}\text { Значение } \\
\text { показа- } \\
\text { теля }\end{array}$ \\
\hline Плотность при $20^{\circ} \mathrm{C}$, г $/ \mathrm{cm}^{3}$ & 1,045 \\
\hline Кинематическая вязкость при 50 ${ }^{\circ}$, мм $^{2} / \mathrm{c}$ & 15,6 \\
\hline Температура перегонки 3\% объема, ${ }^{\circ} \mathrm{C}$ & 195 \\
\hline Доля отгона при 340 ${ }^{\circ}$, мас. \% & 56,5 \\
\hline Массовая доля воды, \% & 0,12 \\
\hline Массовая доля механических примесей, \% & 0,0089 \\
\hline Содержание серы, мас. \% & 0,037 \\
\hline Йодное число, г $\mathrm{I}_{2} / 100$ г & 58,8 \\
\hline
\end{tabular}

Смесь гудрона с ТСП получали путем перемешивания компонентов при температуре $70^{\circ} \mathrm{C}$. Полученную смесь подвергали окислению по известной методике $[12,13]$ при $200^{\circ} \mathrm{C}$, т. е. в относительно мягких условиях, или перед окислением обрабатывали ее СВЧ-полем частотой 2450 МГц в микроволновой печи в течение 7 мин с целью деструкции надмолекулярных образований.

Как известно [18, 19], адгезия (прилипаемость) битума к минеральному материалу зависит от полярности его компонентов. В процессе окисления гудрона наибольшее накопление кислородсодержащих соединений (карбоновых кислот, эфиров), т. е. полярных соединений, наблюдается при температурах до $230^{\circ} \mathrm{C}$. При дальнейшем повышении температуры окисления возрастает доля кислорода, участвующего в образовании воды. Повысить степень структурирования продукта при окислении возможно, если в процессе используются функционализированные аддитивы-модификаторы, способные вступать в реакции с компонентами продукта окисления, например многоатомные спирты [12]. Исходя из химического состава, ТСП может обладать такой способностью.

Основные результаты исследования гудрона с добавкой представлены на рис. 1, 2.

Согласно графическим данным, введение в окисляемый гудрон добавки ТСП в количестве 10 мас. \% позволяет интенсифицировать процесс. При окислении в течение 6 ч получаем продукт, который по значениям температуры размягчения и пенетрации при $25^{\circ} \mathrm{C}$ соответствует требованиям EN 12591 (температура размягчения $43-51^{\circ} \mathrm{C}$, пенетрация 70-100). СВЧ-активация окисляемого сырья на протяжении 7 мин позволяет несколько повысить температуру размягчения, по-видимому, за счет изменения дисперсности окисляемой системы. 


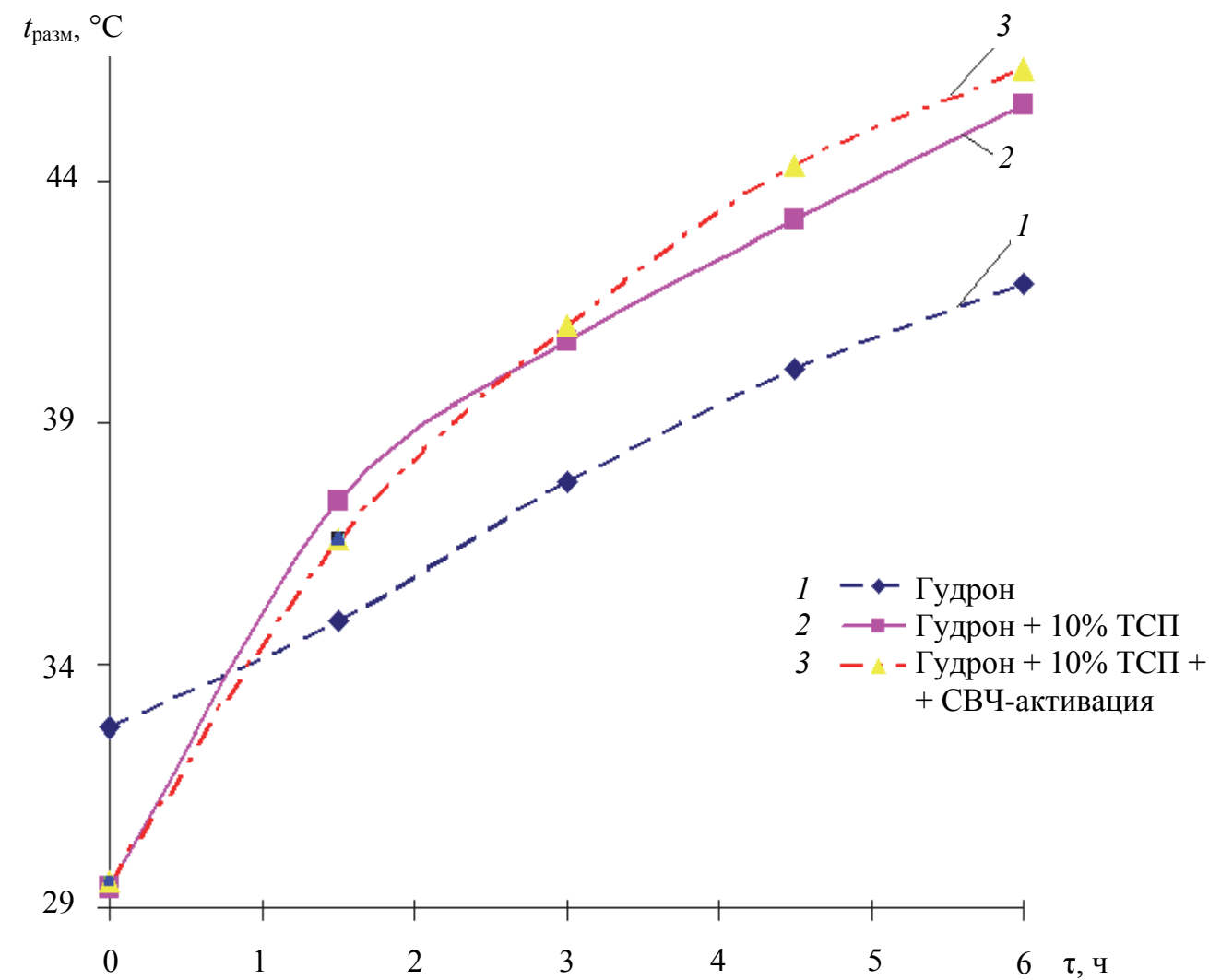

Рис. 1. Зависимость температуры размягчения $t_{\text {разм }}$ от времени окисления $\tau$

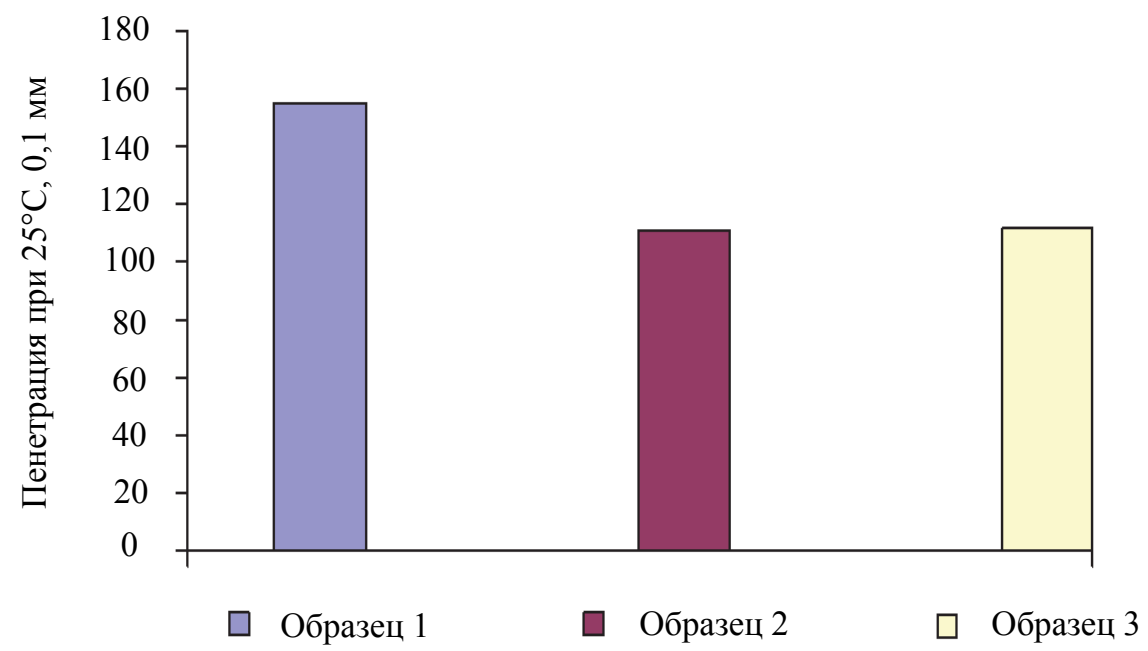

Рис. 2. Пенетрация образцов битума, полученных окислением гудрона (образец 1), гудрона с 10 мас. \% ТСП (образец 2), гудрона с 10 мас. \% ТСП, прошедшего СВЧ-активацию (образец 3 )

Результаты исследований структурно-группового состава исходных и конечных продуктов процесса окисления методом ИК-спектрометрии, выполненные по известной методике [20], приведены в табл. 2.

Из табл. 2 видно, что обработка исходных компонентов сырья СВЧ-излучением практически не влияет на структурно-групповой состав ТСП (опыты № 3 и 4), а вот в гудроне несколько возрастает условное содержание ароматических структур (опыты № 1 и 2). По-видимому, при воздействии на гудрон СВЧ-лучами в некоторой степени разрушаются надмолекулярные агрегаты различных размеров, образованные полициклическими ароматическими структурами, асфальтенами, и одновременно при этом высвобождаются из этих ассоциатов ранее «замкнутые» в них соединения. Этот же эффект проявляется и при обработке смеси гудрона с ТСП СВЧ-излучением перед окислением. 
Структурно-групповой состав продуктов, определенный методом ИК-спектрометрии

\begin{tabular}{|c|l|c|c|c|c|c|c|}
\hline \multirow{2}{*}{$\begin{array}{c}\text { Номер } \\
\text { опыта }\end{array}$} & \multicolumn{5}{|c|}{ Продукт } & \multicolumn{5}{|c|}{ Спектральные коэффициенты } \\
\cline { 3 - 8 } & & $\beta_{1460}^{1600}$ & $\beta_{1600}^{720}$ & $\beta_{1600}^{812}$ & $\beta_{1460}^{1380}$ & $\beta_{1460}^{1030}$ & $\beta_{1460}^{1700}$ \\
\hline 1 & Гудрон & 1,01 & 0,95 & 0,60 & 0,22 & 0,22 & 0,05 \\
\hline 2 & Гудрон (после СВЧ-активации) & 1,09 & 0,90 & 0,64 & 0,23 & 0,25 & 0,07 \\
\hline 3 & ТСП & 0,62 & 1,24 & 0,46 & 0,92 & 0,57 & 0,12 \\
\hline 4 & ТСП (после СВЧ-активации) & 0,62 & 1,23 & 0,46 & 0,92 & 0,57 & 0,13 \\
\hline 5 & Гудрон + 10 мас. \% ТСП (после СВЧ-активации) & 1,07 & 1,00 & 0,59 & 0,21 & 0,23 & 0,05 \\
\hline 6 & Битум из гудрона & 1,14 & 0,77 & 0,63 & 0,23 & 0,26 & 0,11 \\
\hline 7 & Битум из смеси гудрон + 10 мас. \% ТСП & 1,16 & 0,82 & 0,60 & 0,22 & 0,25 & 0,09 \\
\hline 8 & $\begin{array}{l}\text { Битум из смеси гудрон + 10 мас. \% ТСП (после СВЧ- } \\
\text { активации) }\end{array}$ & 1,52 & 0,68 & 0,58 & 0,17 & 0,26 & 0,10 \\
\hline
\end{tabular}

В результате полученный продукт, т. е. окисленный битум, содержит больше ароматических структур по отношению к парафиновым структурам $\left(\beta_{1460}^{1600}\right.$ в опыте № 8 больше, чем $\beta_{1460}^{1600}$ в опыте № 7), что и обусловливает увеличение температуры плавления битумного вяжущего.

Заключение. Согласно результатам проведенных исследований, при окислении гудрона в относительно мягких условиях (температура окисления $200^{\circ} \mathrm{C}$, время окисления 6 ч) совместно с добавкой ТСП последняя позволяет несколько повысить долю ароматических структур в окисляемом гудроне, но это в большей степени связано с увеличением полизамещенных моно- и бициклических углеводородов. Использование при подготовке сырья к окислению СВЧ-излучения позволяет интенсифицировать этот процесс в основном за счет изменения структуры дисперсной системы, сопровождающейся разрушением ассоциативных образований и, соответственно, более благоприятными условиями участия в окислении соединений парафинонафтенового основания.

\section{Список литературы}

1. Окисление остаточных нефтяных дисперсных систем с повышенным содержанием ароматических углеводородов / С. В. Дезорцев [и др.] // Башкирский химический журнал. 2015. Т. 22, № 1. С. 38-45.

2. Интенсификация процесса окисления нефтяного битума / П. К. Змиевский [и др.] // Нефтепереработка и нефтехимия. 1991. № 11. С. 5-6.

3. Усов Б. А., Горбуонова Т. Н. Современные технологии производства дорожных битумов // Системные технологии. 2017. № 22. С. 67-72.

4. Получение окисленного битума на основе модифицированного гудрона / Р. А. Кемалов [и др.] // Нефтепереработка и нефтехимия. 2008. № 7. С. 21-24.

5. Гохман Л. М. Комплексные органические вяжущие материалы на основе блоксополимеров типа СБС. М.: ЗАО «ЭКОН-ИНФОРМ», 2004. 310 с.

6. Джумаева О., Солодова Н. Л., Емельянычева Е. А. Компаундирование в технологиях получения битумов // Вестник технологического университета. 2016. Т. 19, № 5. С. 43-48.

7. Куцуев К. А., Будник В. А. Исследование возможности вовлечения тяжелой пиролизной смолы ЭП-300 в сырье установки производства битумов // Нефтепереработка и нефтехимия. 2012. № 10. С. 14-18.

8. Висбрекинг - остатки как компоненты сырья дорожных битумов / Н. Ю. Белоконь [и др.] // Химия и технология топлив и масел. 2001. № 6. С. 8-10.

9. Вавула Л. В., Ельцев И. П., Ткачев С. М. Возможности получения дорожных битумов улучшенного качества в ОАО «Мозырский НПЗ» // Мир нефтепродуктов. 2007. № 8. С. 20-21.

10. Получение дорожных битумов улучшенного качества на Сызранском НПЗ / В. А. Тыщенко [и др.] // Нефтепереработка и нефтехимия. 2012. № 7. С. 23-26.

11. Использование экстракта селективной очистки в качестве компонента сырьевой смеси при получении окисленного битума / В. Г. Рябов [и др.] // Нефтепереработка и нефтехимия. 2003. № 3. C. $18-21$.

12. Влияние добавки пентаэритрита на свойства нефтяного битумного вяжущего / Е. И. Грушова [и др.] // Труды БГТУ. Сер. 2, Хим. технологии, биотехнологии, геоэкология. 2019. № 2 (223). C. $86-89$.

13. Модификация свойств дорожных вяжущих полимерными отходами / О. В. Куис [и др.] // Труды БГТУ. Сер. 2, Хим. технологии, биотехнологии, геоэкология. 2017. № 2 (199). С. 64-68. 
14. Модификация окислительных колонн установки производства битумов / Н. Ю. Белоконь [и др.] // Нефтепереработка и нефтехимия. 2001. № 4. С. 45-47.

15. Получение окисленных битумов улучшенного качества / С. П. Яковлев [и др.] // Химия и технология топлив и масел. 2003. № 1-2. С. 48-51.

16. Реконструкция окислительного узла битумной установки / А. А. Пранович [и др.] // Нефтепереработка и нефтехимия. 2000. № 12. С. 45-46.

17. Абишев А. А., Загидуллин С. Х. Современные отечественные способы улучшения работы окислительных колонн производства нефтебитумов // Вестник Пермского государственного технического университета. Химическая технология и биотехнология. 2008. № 8. С. 123-130.

18. Гун Р. Б. Нефтяные битумы. М.: Химия, 1973. 432 с.

19. Пажитнова Н. П., Гуревич И. Л. Кислородсодержащие функциональные группы в окисленных битумах // Нефтепереработка и нефтехимия. 1969. № 7. С. 8-10.

20. Применение ИК-спектрометрии в исследовании нефтей / Л. В. Иванова [и др.] // Труды РГУ им. И. М. Губкина. 2010. № 2. С. 76-80.

\section{References}

1. Dezortsev S. V., Telyashev E. G., Petrov A. V., Famutdinov R. N. Oxidation of residual oil dispersed systems with a high content of aromatic hydrocarbons. Bashkirskiy khimicheskiy zhurnal [Bashkir chemical journal], 2015, vol. 22, no. 1, pp. 38-45 (In Russian).

2. Zmievskiy P. K. Intensification of the process of oxidation of petroleum bitumen. Neftepererabotka i neftekhimiya [Oil refining and petrochemistry], 1991, no. 11, pp. 5-6 (In Russian).

3. Usov B. A., Gorbunova T. N. Modern technologies for the production of road bitumen. Sistemnyye tekhnologii [System technologies], 2017, no. 22, pp. 67-72 (In Russian).

4. Kemalov R. A., Petrov S. M., Kemalov A. F. Production of oxidized bitumen based on modified tar. Neftepererabotka i neftekhimiya [Oil refining and petrochemistry], 2008, no. 7, pp. 21-24 (In Russian).

5. Gokhman L. M. Kompleksnyye organicheskiye vyazhushchiye materialy na osnove bloksopolimerov tipa SBS [Complex organic binding materials based on block copolymers of the SBS type]. Moscow, ZAO "EKON-INFORM" Publ., 2004. 310 p.

6. Dzhumaeva O., Solodova N. L., Emel'yanycheva E. A. Compounding in the technologies of receiving bitumens. Vestnik tekhnologicheskogo universiteta [Bulletin of the technological university], 2016, vol. 19, no. 5, pp. 43-48 (In Russian).

7. Kutsuev K. A., Budnik V. A. Investigation of the possibility of involving heavy pyrolysis resin EP-300 in the raw material of the bitumen production plant. Neftepererabotka $i$ neftekhimiya [Oil refining and petrochemistry], 2012, no. 10, pp. 14-18 (In Russian).

8. Belokon N. Yu. The visbreaking - balance components of raw bitumen road. Khimiya i tekhnologiya topliv i masel [Chemistry and technology of fuels and oils], 2001, no. 6, pp. 8-10 (In Russian).

9. Vavula L. V., Tkachev S. M., Yeltsov I. P. Opportunities for road bitumen improved quality at JSC "Mozyr oil refinery". Mir nefteproduktov [World of petroleum products], 2007, no. 8, pp. 20-21 (In Russian).

10. Tyschenko V. A., Kotov S. V., Pogulyko V. A., Zinovieva L. V. Getting road bitumen of improved quality at the Syzran oil refinery. Neftepererabotka i neftekhimiya [Oil refining and petrochemistry], 2012, no. 7, pp. 23-26 (In Russian).

11. Ryabov V. G., Nechaev A. N., Treskov I. A., Makovskay E. V. Use of selective purification extract as a component of the raw material mixture in the production of oxidized bitumen. Neftepererabotka i neftekhimiya [Oil refining and petrochemistry], 2003, no. 3, pp. 18-21 (In Russian).

12. Grushova E. I., Bliznetsov G. D., Haroshka M. A., Stanko M. V. Influence of pentaerythritol additive on the properties of petroleum bitumen binder. Trudy BGTU [Proceedings of BSTU], issue 2, Chemical Engineering, Biotechnologies, Geoecology, 2019, no. 2, pp. 86-89 (In Russian).

13. Kuis O. V., Grushova E. I., Pakhomchik A. S., Yusevich A. I., Dikut' M. V., Shrubok A. O. Modification the properties of road binders polymeric waste. Trudy BGTU [Proceedings of BSTU], issue 2, Chemical Engineering, Biotechnologies, Geoecology, 2017, no. 2, pp. 64-68 (In Russian).

14. Belokon N. Yu., Burlakov S. N., Sutkin S. N., Istomin L. V. Modification of oxidizing columns of bitumen production plants. Neftepererabotka i neftekhimiya [Oil refining and petrochemistry], 2001, no. 4, pp. 45-47 (In Russian).

15. Yakovlev S. P., Loginov S. A., Kosulnikov A. V. Production of oxidized bitumen of improved quality. Khimiya i tekhnologiya topliv i masel [Chemistry and technology of fuels and oils], 2003, no. 1-2, pp. 4851 (In Russian). 
16. Pranovich A. A., Grutski L. G., Peterimov V. V., Grudnikov I. B. Reconstruction of the oxidizing unit of a bitumen plant. Neftepererabotka i neftekhimiya [Oil refining and petrochemistry], 2000, no. 12, pp. 45-46 (In Russian).

17. Abishev A. A., Zagidullin S. H. Modern domestic ways to improve the operation of oxidizing columns of oil bitumen production. Vestnik Permskogo gosudarstvennogo tekhnicheskogo universiteta. Khimicheskaya tekhnologiya i biotekhnologiya [Bulletin of Perm State Technical University. Chemical technology and biotechnology], 2008, no. 8, pp. 123-130 (In Russian).

18. Gun R. B. Neftyanyye bitumy [Petroleum bitumen]. Moscow, Khimiya Publ., 1973. 432 p.

19. Pazhitnova N. P., Gurevich I. L. Oxygen-containing functional groups in oxidized bitumen. Neftepererabotka i neftekhimiya [Oil refining and petrochemistry], 1969, no. 7, pp. 8-10 (In Russian).

20. Ivanova L. V., Sopheva R. Z., Koshelev V. N. Application of IR spectrometry in oil research. Trudy $R G U$ imeni I. M. Gubkina [Proceedings of Gubkin Russian State University], 2010, no. 2, pp. 76-80 (In Russian).

\section{Информация об авторах}

Грушова Евгения Ивановна - доктор технических наук, профессор кафедры нефтегазопереработки и нефтехимии. Белорусский государственный технологический университет (220006, г. Минск, ул. Свердлова, 13a, Республика Беларусь). E-mail: grushova.e@mail.ru

Станько Марина Викторовна - выпускник. Белорусский государственный технологический университет (220006, г. Минск, ул. Свердлова, 13a, Республика Беларусь). E-mail: marishka. stanko@yandex.ru

Хатько Ирина Николаевна - студентка. Белорусский государственный технологический университет (220006, г. Минск, ул. Свердлова, 13а, Республика Беларусь). E-mail: ikhatko@gmail.com

\section{Information about the authors}

Grushova Evgeniya Ivanovna - DSc (Engineering), Professor, the Department of Oil and Gas Processing and Petroleum Chemistry. Belarusian State Technological University (13a, Sverdlova str., 220006, Minsk, Republic of Belarus). E-mail: grushova.e@mail.ru

Stan'ko Marina Viktorovna - graduate. Belarusian State Technological University (13a, Sverdlova str., 220006, Minsk, Republic of Belarus). E-mail: marishka.stanko@yandex.ru

Khat'ko Irina Nikolaevna - student. Belarusian State Technological University (13a, Sverdlova str., 220006, Minsk, Republic of Belarus). E-mail: ikhatko@gmail.com 